\title{
Haitian Epistemology, Phenomenological Structuralism, and Resolving the Binding and Hard Problems of Consciousness
}

\author{
Paul C Mocombe* \\ West Virginia State University, The Mocombeian Foundation, USA
}

*Corresponding author: Paul C Mocombe, West Virginia State University, The Mocombeian Foundation, USA.

Received Date: July 22, 2019

Published Date: August 23, 2019

\section{Abstract}

The hard problem of consciousness, introduced in the discourse of consciousness constitution by David Chalmers (1995), seeks to understand how and why sentient beings have phenomenal experiences or felt states like pain, excitement, heat, etc. This latter problem is tied to the binding problem, which seeks to understand what accounts for the unity of experience. The understanding here is that the solution to the latter will resolve the problem of the former. In this work I explore the nature of the hard and binding problems of consciousness in Paul C. Mocombe's structurationist theory of phenomenological structuralism. The author utilizes the concept of the nanm in Haitian epistemology as constituted in his theory of phenomenological structuralism to resolve both problems of consciousness. Mocombe concludes that what accounts for the unity of experience is the psychion, subatomic particle, of an emergent psychonic/panpsychic subatomic field of the multiverse that has phenomenal properties, which gets embodied as neuronal particles of the aggregated brain, which experiences a material resource framework as an "I" whose phenomenal properties following matter disaggregation either returns back to the field or collapses in other worlds where the same matter exists.

Keywords: Haitian Epistemology; Structurationism; Praxis; Panpsychism; Social Class Language Game; Phenomenological Structuralism; ORCHOR Theory

\section{Introduction}

The hard problem of consciousness, introduced in the discourse of consciousness constitution by David Chalmers [1], seeks to understand how and why sentient beings have phenomenal experiences or felt states like pain, excitement, heat, etc. This latter problem is tied to the binding problem, which seeks to understand what accounts for the unity of experience. The understanding here is that the solution to the latter will resolve the problem of the former. In this work I explore the nature of the hard and binding problems of consciousness in Paul C. Mocombe's structurationist theory of phenomenological structuralism. The author utilizes the concept of the nanm in Haitian epistemology as constituted in his theory of phenomenological structuralism to resolve both problems of consciousness. Mocombe concludes that what accounts for the unity of experience is the psychion, subatomic particle, of an emergent psychonic/panpsychic subatomic field of the multiverse that has phenomenal properties, which gets embodied as neuronal particles of the aggregated brain, which experiences a material resource framework as an "I" whose phenomenal properties following matter disaggregation either returns back to the field or collapses in other worlds where the same matter exists.

\section{Background of the Problem}

Consciousness here refers to subjective awareness of phenomenal experiences (ideology, language, self, feelings, choice, control of voluntary behavior, thoughts, etc.) of internal and external worlds. The academic literature "describes three possibilities regarding the origin and place of consciousness in the universe: (A) as an emergent property of complex brain neuronal computation, (B) as spiritual quality of the universe, distinct from purely physical actions, and (C) as composed of discrete 'proto-conscious' events acting in accordance with physical laws not yet fully understood" (Hameroff and Penrose, 2014, pg. 70). The latter position, (C), represents the ORCH-OR ("orchestrated objective reduction") theory of Stuart Hameroff and Roger Penrose [2], which includes 
aspects of (A) and (B), and posits that "consciousness consists of discrete moments, each an 'orchestrated' quantum-computational process terminated by... an action [,objective reduction or $\mathrm{OR}$,] rooted in quantum aspects of the fine structure of space-time geometry, this being coupled to brain neuronal processes via microtubules" (pg. 70). In this view, the understanding is that a proto-conscious experience existed in the early universe, panpsychism, and as a result of emergent structures of the brain it (proto-conscious experience, psychion) became embodied and evolved as a result of quantum neuronal computations of "brains".

Paul C. Mocombe's [3-5] 2018, structurationist sociology, phenomenological structuralism, which attempts to resolve the structure/agency problematic of the social sciences, builds on the ORCH-OR theory and panpsychism of Hameroff and Penrose, while holding on to the multiverse hypothesis of quantum mechanics and Haitian ontology/epistemology, which the authors reject, the former, because it is not "a more down-to-earth viewpoint" [3]. For Mocombe [3,4] 2018, quantum superposition, entanglement, and evidence in Haitian Vodou of spirit possession, which represent ancestors from a parallel world, Vilokan, of the earth's of which we ought to pattern our behaviors and structures, are grounding proofs for the acceptance of the multiple worlds hypothesis of quantum mechanics within an M-theory interpretation of the constitution of the multiverse. Within the latter hypothesis, the understanding is that "each possibility in a superposition evolves to form its own universe, resulting in an infinite multitude of coexisting 'parallel' worlds. The stream of consciousness of the observer is supposed somehow to 'split', so that there is one in each of the worlds-at least in those worlds for which the observer remains alive and conscious. Each instance of the observer's consciousness experiences a separate independent world and is not directly aware of any of the other worlds" [3]. It is within this multiple world, which are materially real, hypothesis that Mocombe constitutes the notion of consciousness in the universe according to his theory of phenomenological structuralism. For Mocombe, the material world is real and objective, and the informational content of consciousness is epiphenomenal content recycled/entangled/ superimposed throughout the multiverse after matter aggregation and experience. Consciousness is an emergent fifth force of nature, a quantum material substance/energy, psychion, the phenomenal property of which is recycled/entangled/superimposed throughout the multiverse and becomes embodied via the microtubules of brains. It is manifested in simultaneous, entangled, superimposed, and interconnecting material resource frameworks as embodied praxis or practical consciousness, which in-turn becomes the phenomenal properties of material (subatomic particle energy, psychion) consciousness that is recycled/entangled/superimposed throughout the multiverses via (self-aware or not) practical activity and the phenomenal properties of subatomic particles of a psychonic/panpsychic field, which goes on to produce aggregated matter with consciousness.

In other words, Paul C. Mocombe's 2018 [5] structurationist theory of phenomenological structuralism, in keeping with the logic of structurationist sociology, assumes practical activity and consciousness, i.e., practical consciousness, to be the basis for understanding human behavior and consciousness in the world. For Mocombe, this consciousness is neither an emergent illusion of the brain or one that comes from a simulation of species-Beings with "higher consciousness" than our human form, nor a God, which animates our species-being with its essence that is our human soul/ consciousness. The aforementioned positions, a simulation/virtual reality, emergent property of the mechanical brain, or the essence of God, presupposes the existence of consciousness as fundamental to the multiverse prior to its embodiment as the "I," the Cartesian thinking subject, of the human actor. In Mocombe's theory of phenomenological structuralism, consciousness, like the other forces of the multiverse, is presupposed as a proto-evolutionary force with a subatomic field whose particles become embodied via microtubules of brains. In other words, consciousness is an emergent fifth force of nature, a psychion of a psychonic/panpsychic subatomic field, which evolves via experience of the macro-world as embodied aggregated neuronal energy, in microtubules of brains, recycled/entangled/superimposed throughout the multiverses. Hence, it is not solely an emergent property of the mechanical brain; a simulation (virtual reality) wherein sentient beings with consciousness are the pawns in the conscious scenarios of a species-being with higher-consciousness; nor is it a product of a God, in the Christian sense, animating it in its consciousness. Even if the latter two (which makes up the virtual reality hypothesis in some physic circles) were the case, neither would deny the fact that we are able to know the laws of the "material" simulation by which we become conscious or have consciousness, which appears to be fundamental prior to time and space of the macro-worlds. I disagree with this virtual reality hypothesis of the multiverse. For me, the multiverse is real and objective, and consciousness is not fundamental to it. Instead, consciousness is, like time and space, an emergent property of the macro-world, which evolves as a force of nature akin to the evolution of gravity. In other words, it becomes an emergent force of nature, which is recycled/entangled/ superimposed throughout the multiverse, after the constitution of the macro-world: consciousness is the product of neuronal energies, psychion, of a psychonic/panpsychic subatomic field, the phenomenal properties of which aggregate as matter, via the other forces of nature, and manifests itself in the multiverse as embodied practical activity, i.e., practical consciousness, of species, whose consciousness, once disaggregated as matter in one universe, either collapses unto other versions of itself that exists in other multiverses, or is recycled into the psychonic/panpsychic subatomic field as particles with phenomenal properties. So, the phenomenal properties of subatomic particles is the binding elements that give unity to consciousness in the brains of sentient beings, which experience this unity as neuronal phenomenal experience of an "I" in order to experience and exist in a material resource framework.

\section{Theory \& Method}

Paul C. Mocombe's [3-6] phenomenological structural ontology seeks to fix structurationist sociology to account for the structure/ 
agency problematic of the social sciences by synthesizing the materialism of physics, quantum mechanics in particular, with the agential initiatives highlighted in the phenomenological discourses of Husserl, Heidegger, Merleau-Ponty, and Sartre (which parallels the phenomenology found in Haitian/Vilokan Idealism for Mocombe), the Neo-Marxist structuralism of structurationism and Althusser, and Wittgenstein's notion of language game (the latter two to capture the reification of the subjectivity of the phenomenal world via society by those who consolidate and control its resources). It is the metaphysics of Haitian idealism, its phenomenology, and antidialectical viewpoint of Haitian social practice, which Mocombe attempts to tie to the phenomenology of German idealism, which it parallels in his structurationist theory and methodology, and the aforementioned theoretical perspectives [6]. Mocombe builds on Haitian epistemology's notion of the nanm to understand the constitution of consciousness as a proto-material substance of the multiverse whose phenomenal properties, once disaggregated as aggregated matter, constitutes a psychonic/panpsychic field the psychion of which gives unity to our experiences and felt experiences once embodied. Hence like Haitian/Vilokan Idealism which posits that the nanm, which provides unity to our experiences is a material thing, a Cartesian I composed of three distinct entities (sometimes more as Haitian metaphysics suggests that a fourth entity, lwa met tet, may constitute the nanm of serviteurs in order to guide them in their decision-making) that are also tied to the natural world and can be manipulated in life as well as death. I, also, view consciousness as a proto-material substance, which becomes embodied.

As the late ATI-oungan of Vodou, Max Beauvoir (2006), highlights about the nanm, the human being is a sentient being, which is constituted as three distinct material entities, the physical body, the gwo bon anj (sé médo), and the ti bon anj (sé lido). The latter two constitute our nanm (soul), and the physical body is aggregated matter that eventually dies and rots. It is animated by the energy force of Bon-dye or the universe, the gwo bon anj, which is not active in influencing personality or the choices that the human subject makes in life. Instead, it is simply the spark of life or the energy force that keeps the body living or activated. In other words, metaphorically speaking, imagine the body as an electrical cord, Bon-dye as the socket, and the spark of energy from the socket that animates the appliance as the gwo bon anj.

The animated body, the physical body and the gwo bon anj, gives rise to consciousness and the personality through the ti bon anj. The most important part of the body is the head, which is the seat of consciousness and the space where sight, hearing, smell, and taste all reside. The five senses of the head, and the brain's reflection on what is smelled, heard, seen, tasted, and touched gives rise to the ti bon anj, which is consciousness, intellect, reflection, memory, will, and the personality. That is to say, it is the ti bon anj that houses the ego, self, personality, and ethics of the person from experiences in life. So, the gwo bon anj animates the physical body, which gives rise to the ti bon anj, i.e., the individual ego or I of a human subject as they experience being in the world with others.
The three aforementioned distinct (materialist) entities constitute the average individual and can be separated at various points throughout their life cycle and at the time of death. As previously mentioned, people who are called to work with lwa yo (spirits and concepts in Haitian Vodou) also have a fourth entity, personal lwa, mét tét, who permanently resides within their head, i.e., a sort of split personality that guides the individual in making important and daily decisions. For the average individual, at the time of death the physical body dies and rots, the ti bon anj, the ego, personality, etc., returns to Ginen (Africa), Vilokan, and the gwo bon anj lingers around seeking to animate a new body. Serviteurs, oungan yo, Manbo yo, and Bokor yo, can work to bring the ti bon anj of elders back across the waters from Africa so that they can be an active and honored ancestor. This latter process of ancestor retrieval is usually done a day and a year after the death of the person, and requires an animal sacrifice, i.e., the taking of a life to feed lwa yo in order to retrieve the deceased ancestor from Ginen. Upon retrieval, the ti bon anj of the ancestor is kept in a govi, a small clay bottle. Bokors, sorcerers, who are members of secret societies in Vodou, and stand apart from oungan yo (priests) and Manbo yo (priestesses) as sorcerers who serve Petwo lwa yo, can also capture the lingering ti bon anj to do spiritual work aimed at healing, ascertaining money, love relationships, work , political power, i.e., pwen, or other desires. This latter act is one form of zombification wherein the ti bon anj of a deceased person is captured in a bottle, govi, in directed to serve either the Bokor or an individual seeking wealth, love, political power, or to do harm to another person, etc.

Aside from separation in death, separation can also take place during a person's life cycle. During a person's life cycle, the gwo bon anj can be displaced by a lwa during possession or a Bokor for zombification. The lwa utilizes the animated body (the person possessed is called a chawl or horse for the lwa) to experience the world, heal, protect, etc. The ti bon anj can be displaced during a person's life cycle by a Bokor for the mitigation of punishment through zombification. This latter action is essentially the death penalty in Vodou when individuals morally violate nature, communal life, or an individual. Bokor yo are called upon by oungan yo and manbo yo to punish the transgressor through the removal of their ti bon anj from their bodies. During this process, the ego and personality, ti bon anj, is removed, and the person is left with the material body and the gwo bon anj. The purpose of this act is to render the transgressor without the desire and drive to commit any further acts, which arose from their ti bon anj. The person is not killed, but the desire and passion that caused them to commit the initial transgression that they committed is removed. Hence the person is left alive as a mindless zombie. Essentially, whereas oungan yo, manbo yo, and gangan/dokté fey are the readers, judges, and healers, Bokor yo are the sorcerers and police force of the village. They are practitioners of black magic, and are visited by people seeking to do harm to someone, wealth, power, luck, revenge, etc. There are three other, external, cosmic force and lwa yo that impact the individual. They are the zetwal, i.e., the star of a person, which determines their fate; the lwa rasin, or lwa eritaj, 
the spirit of the ancestors "who enter the path of the unconscious to talk to him or her in dreams, to warn of danger, and to intervene at the many levels of his [or her] life"; and the wonsiyon, "these are a series of spirits that accompany the lwa mét tét and modify somewhat the amplitude and the frequencies of its vibration or presence" (Beauvoir, 2006) [7-11].

Like Haitian ontology, highlighted by Max Beauvoir, I am a materialist, and view consciousness in similar material terms. For me, all aggregated matter in our dispensation of spacetime is composed of subatomic particle energies. Thus, to understand the constitution and origins of human practical consciousness one must begin with not only the actions (phenomenal properties) associated with these particles, but their essence or intrinsic nature, which is their inner conscious life (i.e., panpsychism), prior to understanding the sociocultural factors, which emerge as a result of matter aggregation and being-in-the-world.

In other words, subatomic particles have or is consciousness (a material emergent fifth force of nature), which becomes embodied during their aggregation via the proposed Higgs-Boson field, i.e., God particle. According to the tenets of quantum physics as reflected in supersymmetry theory, dark matter, parallel universes (multiverses), and the EPR (Einstein, Podolsky, and Rosen) paradox, the universe is composed of ordinary matter (atoms and molecules) and dark matter (axions, wimps, neutrinos, bosons, and fermions). Dark matter, as opposed to ordinary matter, constitutes over eighty percent of the material substance that constitute the cosmos. This dark matter is not constituted by atoms and molecules like ordinary matter but consists of subatomic particles and energy. The particles in the nature of quarks are identified as wimps or axions, very tiny particles that contribute to the formation of nuclear components. These tiny particles are conceived of as coiled energies, strings of space-time, packets of energy-like photons. They are physical in nature but immaterial, and coexist, in a parallel/alternate universe, with ordinary matter in the same location without impediment or interference. They belong to the fermion family of invisible particles whose counterparts are named a boson, which is pure energy. So, as highlighted in supersymmetry theory, for every boson particle of matter, a symmetry counterpart, fermion, exists which manifests itself as force or energy. Thus, for every reality we discover in the solid world around us, we must assume that there exists a symmetric counterpart, or boson, which is invisible but is nevertheless as physical as its visible counterpart. These supersymmetric doubles constitute the backbone of alternate realities, parallel universes that are displayed in ten dimensions, including our ordinary three-dimensional Cartesian reality. Moreover, according to quantum theory, these particles have psychic properties (Frankish, 2016). That is, the particles are conscious, i.e., panpsychism. They have phenomenal properties and are aware of their position, of themselves, and of their surroundings. In other words, the multiverse created by these particles are endowed with consciousness and phenomenal properties emanating from a psychonic/panpsychic subatomic particle field whose information can never be destroyed, is immortal in principle, get recycled/ entangled/superimposed throughout the multiverse, and becomes embodied [12-16].

These phenomenal properties coupled with the consciousness of subatomic particles, according to Mocombe, help to explain the magic of action-at-a-distance highlighted in the physics of quantum mechanics, which contradicts action in real space and time and simultaneity as suggested by Albert Einstein's theory of general relativity, thus making the two physics incompatible. So in phenomenological structural sociology Mocombe interprets the quantum fact that the two phenomenon happening in the quantum world, i.e., one mathematical rule for the external objective world before a measurement is made, and another that jumps in after the measurement occurs by an observer, by siding with the psi-ontologists as Christopher Fuchs calls them, who want the wave function to describe the objective world, over the psiepistemologists who see the wave function as a description of our knowledge and its limits [6]. In the former, also known as wavefunction realism, the understanding is that we live in a multiverse of many-worlds or parallel universes (similar to the connection between Vilokan and the world of earthly actions as seen in Haitian Idealism). Measurements do not suspend the equation or collapse the wave function, "they merely made the Universe split off into many (perhaps infinite) parallel versions of itself. Thus, for every experimentalist who measures an electron over here, a parallel universe is created in which her parallel copy finds the electron over there" (Frank, 2017). The latter, psi-epistemologists, suggests physics is no longer a description of the world in-and-of itself. Instead, it's a description of the rules for our interaction with the world, i.e., the perceiving subject determines the objective rules of physics [6].

In other words, according to quantum mechanics in contradistinction to Einstein's EPR paradox and theory of general relativity associated with the psi-epistemologists, which argued against quantum theory's action-at-a-distance, subatomic particles are recycled/entangled/superimposed throughout the multiverses maintaining, based on the assumption of panpsychism, the contents of their aggregated existence, i.e., experiences throughout the multiverses, as phenomenal property of a psychonic/panpsychic subatomic field. This, for Mocombe, helps to explain Schrodinger's wave function mathematical entity, "which seemed to allow the position of an unmeasured particle to be spread out across an arbitrarily large region of space. When the particle's position was measured, the wave function was said to 'collapse', suddenly becoming localized where the particle was detected. Einstein objected that if this collapse was a real physical process, it would reintroduce action-at-a-distance, and so be incompatible with special relativity" (Price and Wharton, 2016). For Einstein, all that has occurred is not action-at-a-distance, but our information about the particle, and not the particle itself has changed. For Mocombe, in building on the logic of quantum mechanics and panpsychism associated with the psi-ontologists, which suggests that the particles have phenomenal properties and are conscious, the particle itself, impacted by the physical processes of the observer, 
chooses to change under observation or is visible within the rules of the material resource framework it is being observed. Physics and the physical sciences highlight the actions of the observable matter, but not what it is intrinsically, which is an emergent fifth force in and of nature, mainly, consciousness and its aggregated experiences recycled, entangled, and superimposed in other multiverses simultaneously with the observable matter [17-25].

Hence the logical consequence regarding the evolution and constitution of the multiverses, and their contents, based on the assumptions of action-at-a-distance, phenomenal properties, and panpsychism, for Mocombe, is similar to the intersecting worlds theory highlighted in Haitian Vodou, which parallels the physics, "membrane theory," of Lisa Randall and Raman Sundrum (1999). The proposal in keeping with the logic of Haitian Vodou and the "brane theory" of Randall and Sundrum is that there might be an additional dimension on the cosmological scale, the scale described by general relativity, which gives rise to four dimensional (layered) multiverses within it. That is to say, our universe is embedded in a vastly bigger five-dimensional space (the four-dimensional space of relativity, plus a fifth dimension for the subatomic forces including consciousness), a kind of super-universe. Within this super-space, our universe is just one of a whole array of co-existing universes (Haitian Vodou only accounts for our universe), each a separate four-dimensional bubble within a wider arena of five-dimensional space where consciousness (a subatomic force) is recycled/ entangled/superimposed between the five-dimensional superspace, i.e., superverse, and its multiverses.

For Mocombe the multiverses originated, from the superuniverse, either by fiat or quantum fluctuation. They are bosonic forces that were brought forth together with fermion counterparts. They are also the primeval psychonic/pan-psychic field, stemming from the super-verse, whose fermion can be called a psychion, a particle of consciousness. These have evolved together to produce the four forces of nature, electromagnetic force; gravity; the strong nuclear force; and weak nuclear force, in our universe, which in turn produced atoms, molecules, and aggregated life endowed with the recycled/superimposed/entangled consciousness and phenomenal properties of the primeval pan-psychic fields of the superverse and its multiverses. In other words, according to quantum mechanics subatomic particles of energy constitute all the matter of our universe via the Higgs Boson Field, i.e., the god particle, which objectifies and materialize the matter that we are, see, hear, taste, feel, and touch. Subatomic particles constitute our material bodies and consciousness as neuronal energies, which constitute and operate the brain and the body (Hameroff and Penrose, 2014). However, subatomic matter, which are strings/ waves at the subatomic particle level, operate differently from observable objectified energy, matter, in that their behavior are indeterminate and can exist in multiple places, dimensions or parallel universes, simultaneously prior to being observed or even during observation as aggregated matter. In fact, the subatomic particles that constitute our material bodies and consciousness as neuronal energies are the same subatomic particles that constitute everything that we consider to be the world, universe, other species, etc. At the subatomic particle level, we are not subjects contemplating an object, i.e., the world, multiverse, etc., we are the world, an undifferentiating energy of probabilities, endowed with recycled/superimposed/entangled consciousness and phenomenal properties, which are immortal in principle. Hence, the implication suggested by the Standard Model of physics is that the observable and non-observable matter that constitutes our universe exists elsewhere in other unseen dimensions and parallel universes simultaneously with our own dispensation of space-time. We do not occupy a universe. We are part of a superverse and multiverse with a plethora of I (s) and other sentient beings, or not, existing in them indistinguishable from one another at the subatomic level as recycled/entangled/superimposed energy. They become distinguishable at the atomic level through subatomic particle aggregation, i.e., matter. Subatomic particles aggregate to form objectified matter, universes, worlds, species and sentient beings, etc., as a result of the five forces of nature (electromagnetism, gravity, the strong and weak nuclear forces, and consciousness). The plethora of I (s) and other sentient beings are constituted and connected via subatomic particles that are recycled/entangled/ superimposed throughout and as the superverse and multiverse to constitute and operate consciousness as subatomic neuronal energies of the body and the brain, which encounters objectified matter as objectified matter in simultaneously existing worlds of the multiverses via the actions and senses of the brain, body, language, ideologies, ideological apparatuses, and communicative discourse. In essence, consciousness is recycled/superimposed/ entangled subatomic energies of the multiverses objectified and embodied, similar to the nanm in Haitian idealism and Hegel's conceptualization of Geist. Whereas for Hegel Geist is distinct from the world and unfolds dialectically in it, via embodiment of certain individuals, towards an ever-increasing rationalization of the world. For Mocombe the historical manifestation, Beingin-Spacetime, of the objectification of subatomic particles of the multiverse as consciousnesses and bodies has no definitive endgoal and is indeterminate, but constrained in materialized spacetime by material bodies (forms of sensibility and understanding) and among the human species power relations or the social class language games of those whose objectification or historicity precedes individual consciousnesses and control the economic (material) conditions (and mode of production) of a material resource framework [26-32].

\section{Discussion and Conclusion}

So, for Mocombe the multiverse is objective and real. There is no God in the multiverse (even if there was one, who created us as part of a simulation (virtual world) that is the multiverse, it would not matter or prevent us from understanding the rules and laws explaining the emergence and role of consciousness in the simulation), just consciousness, emanating from a psychonic or pan-psychic subatomic field, becoming and being in simultaneously existing present/past/future layered worlds, which are entangled and superimposed. The initial superverse, which created the 
multiverse is a product of quantum fluctuation of dark matter and energy, which funneled or exploded to create multiverses via the first four forces of nature, with consciousness being a later (evolutionary) force that emerged following species formation (matter aggregation) and death. That is, the superverse creates layered multiverses each interconnected via subatomic particles, which aggregated, via the initial four forces of nature, to form macro-worlds. Over time sentient beings experiencing these objective worlds emerged, and the phenomenal properties of their subatomic particles were recycled upon matter disaggregation to constitute a psychonic/panpsychic field of the superverse, which would make consciousness an emergent (evolutionary) fifth force of nature endowing future sentient beings with consciousness, a fifth (evolutionary) force of nature. This consciousness is a neuronal energy field, which is not destroyed when matter is disaggregated; instead, it is either recycled into the psychonic/panpsychic subatomic field of the superverse, or entangled and superimposed into its counterparts where the disaggregated matter still exists in its aggregated forms in the multiverse. In the human ethos of the macro-world, the psychonic/pan-psychic subatomic field that is consciousness becomes God, which is associated with attributes that we embody or must embody in order to reproduce our being in material resource frameworks.

Generally speaking, consciousnesses, actions (practical consciousness), learning, and development within Mocombe's phenomenological structural ontology are the product of the embodiment of the phenomenal properties of recycled/entangled/ superimposed subatomic neuronal energies/chemicals, psychion, of the multiverse objectified in the space-time of multiverses via the aggregated body and the microtubules of the brain. Once objectified and embodied the phenomenal properties of the neuronal energies/chemicals encounter the space-time of physical worlds via a transcendental subject of consciousnesses (the aggregation of a universal-self superimposed and entangled across the multiple worlds of the multiverse) and the drives and sensibilities of the aggregated body and brain in reified structures of signification, language, ideology, ideological apparatuses, and communicative discourse defined and determined by other beings that control the resources (economics), and modes of distributing them, of a material world required for physical survival in spacetime. The Heideggerian (mental) stances/analytics, "ready-tohand," "unready-to-hand," and "present-at-hand," which emerge as a result of conflict between the embodied transcendental ego vis-à-vis its different systems, 1) the sensibilities and (chemical, biological, and physiological) drives of the body and brain, 2) drives/impulses of embodied residual memories or phenomenal properties of past recycled/entangled/superimposed subatomic/ chemical particles, 3) the actions produced via the body in relation to the indeterminacy/deferment of meaning of linguistic and symbolic signifiers as they appear to individuated consciousnesses in ego-centered communicative discourse, 4) and the dialectical and differentiating effects, i.e., structural reproduction and differentiation, of the structures of signification, social class language game, of those who control the economic materials (and their distribution, i.e., mode of production) of a world are the origins of practical consciousnesses. All four types of actions, the drives and sensibilities of the body and brain, drives or phenomenal properties of embodied recycled/entangled/superimposed past consciousnesses, structural reproduction/differentiation stemming from the mode of production, and deferential actions arising from the deferment of meaning in ego-centered communicative discourse via the present-at-hand stance/analytic, exist in the material world with the social class language game, i.e., the physical, mental, emotional, ideological, etc. 5) powers of those who control the material resource framework as the causative agent for individual behaviors. In other words, our (mental) stances in consciousness vis-à-vis the conflict between the (chemical, biological, and physiological) drives and sensibilities of the body and brain, (societal) structural reproduction and differentiation, drives of embodied past/present/future consciousnesses of recycled/ entangled/superimposed subatomic/chemical particles, and deferential actions arising as a result of the deferment of meaning in ego-centered communicative discourse determines the practical consciousness we want to recursively reorganize and reproduce in the material world. The power and power positions of those who control (via the mode of production, language, ideology, ideological apparatuses, and communicative discourse) the resources (and their distribution, i.e., mode of production) of a material resource framework, and the threat it poses to the ontological security of an actor, in the end determines what actions and identities are allowed to organize and reproduce in the material world without the individual actor/agent facing marginalization or death [33-38].

It is Being's (mental/cognitive) stance/analytic, "ready-tohand," "unready-to-hand," and "present-at-hand," in consciousness vis-à-vis the conflict, or lack thereof, between the (chemical, biological, and physiological) drives and sensibilities of the aggregated body and brain, drives/impulses (phenomenal properties) of residual past/present/future consciousnesses of recycled/entangled/superimposed subatomic particles, alternative practices which arise as a result of phenomenological meditation and deferment of meaning, along with the differentiating logic or class divisions of the social relations of production, which produces the variability of actions and practices in cultures, social structures, or social systems. All four types of actions are always present and manifested in a social structure to some degree contingent upon the will and desires of the economic social class that controls the material resource framework through its body (practical consciousness), language/symbols, ideology, ideological apparatuses, and social relations of production. They choose, amidst the class division of the social relations of production, what other meaning constitutions and practices are allowed to manifest themselves in the material world without facing alienation, marginalization, domination, or death.

Hence, we never experience the things-in-themselves of the world culturally and historically in consciousness. We experience them structurally or relationally, the structure of the conjuncture 
of the mode of production, its language, ideology, ideological apparatuses, etc., and our (mental/cognitive) stances/analytics, ready-to-hand, unready-to-hand, present-at-hand, vis-à-vis these things as they appear to and in consciousness determine our practical consciousness or behaviors.

We initially know, experience, and utilize the things of and in consciousness in the preontological ready-to-hand mode, which is structural and relational. That is, our bodies encounter, know, experience, and utilize the things of the world in consciousness, intersubjectively, via their representation as objects of knowledge, truth, usage, and experience enframed and defined in the relational logic and practices or language game (Wittgenstein's term) of the institutions or ideological apparatuses of the other beings-ofthe-material resource framework whose historicity comes before our own and gets reified in and as the actions of their bodies, language, ideology, ideological apparatuses, mode of production, and communicative discourse. This is the predefined phenomenal structural, i.e., ontological, world we and our bodies are thrown-in in coming to be-in-the-world. How an embodied-hermeneuticallystructured Being as such solipsistically view, experience, understand, act, and utilize the predefined objects of knowledge, truth, and experienced defined by others and their conditions of possibilities in consciousness in order to formulate their practical consciousness is albeit indeterminate. Martin Heidegger in Being in Time is accurate, however, in suggesting that three stances or modes of encounter (Analytic of Dasein), "presence-at-hand," "readiness-to-hand," and "un-readiness-to-hand," characterizes our views of the things of consciousness represented intersubjectively via bodies, language, ideology, and communicative discourse, and subsequently determine our practical consciousness or social agency. In "ready-to-hand," which is the preontological mode of human existence thrown in the world, we accept and use the things in consciousness with no conscious experience of them, i.e., without thinking about them or giving them any meaning or signification outside of their intended usage. Heidegger's example is that of using a hammer in hammering. We use a hammer without thinking about it or giving it any other condition of possibility outside of its intended usage as defined by those whose historicity presupposes our own. In "present-at-hand," which, according to Heidegger, is the stance of science, we objectify the things of consciousness and attempt to determine and reify their meanings, usage, and conditions of possibilities as the nature of reality as such. Hence the hammer is intended for hammering by those who created it as a thing solely meant as such. The "unready-to-hand" outlook is assumed when something goes wrong in our usage of a thing of consciousness as defined and determined by those who adopt a "present-at-hand" view. As in the case of the hammer, the unreadyto-hand view is assumed when the hammer breaks and we must objectify it, by then assuming a present-at-hand position, and think about it in order to either reconstitute it as a hammer, or give it another condition of possibility. Any other condition of possibility that we give the hammer outside of its initial condition of possibility which presupposed our historicity becomes relational, defined in relation to any of its other conditions of possibilities it may have been given by others we exist in the world with who either readyto-hand, unready-to-hand, or present-at-hand attempts to maintain the social class language game of power. In the ready-to-hand stance the latter unconsciously practices and attempts to reproduce the social class language game of power by discriminating against and marginalizing any other conditions of possibilities of their social class language as determined by those in ideological power positions. They may move to the unready-to-hand stance in response to those who they encounter that attempts, presentat-hand, to alter the nature of the dominant social class language game they recursively reorganize and reproduce as outlined by those in power positions who are present-at-hand of the dominant social class language game. In either case, not all beings achieve the present-at-hand stance. The latter is the stance of science and ideologies, which are tautologies when they profess that their stances represent the nature of reality as such, and those in power positions, who choose, among a plethora of alternative presentat-hand social class language games, what alternative practical consciousnesses outside of their social class language game that are allowed to manifest in the material world.

Hence, as outlined above, phenomenological structuralism posits consciousness to be the by-product or evolution of subatomic particles unfolding with increasing levels of abstraction within a material resource framework enframed by the mode of production, language, ideology, ideological apparatuses, and communicative discourse of bodies (who control the material resource framework) recursively reorganizing and reproducing the ideals of the latter factors as their practical consciousness. Thus, in phenomenological structuralism the understanding is that the structure of reality determines language (via its generative grammar) and how we ought to live in the world. However, the language, and its usage, i.e., social class language game, of those who control the material resource frameworks of the world conceals that relationship via their mode of production, ideologies, ideological apparatuses, and communicative discourse, which is evolutionary. In other words, like the Wittgensteinian position of the Tractatus, Mocombe's theory of phenomenological structuralism assumes that there is a uniform (grammatical) structure to language determined by the logical-empirical structure of (quantum and physical) reality. The grammatical structure of linguistic utterances attempts to capture the subjects and objects of that reality and how we ought to live in it and with them. In being-in-the-world with others, this logicalgrammatical structure, however, is concealed by the developmental knowledge, and its usage (practical activity), of those who control the material resource framework of the world via the stage of development of their language, ideology, ideological apparatuses, social relations of production, and communicative discourse. Be that as it may, the latter comes to constitute an evolutionary social class language whose linguistic systemicity and usage comes to determine our conception of reality, and the classes, categories, and forms of life we belong to and interact in and with, which depending on its stage of development and relation to the True nature of 
reality as such, is either accepted or constantly deferred by those in its speech community who are marginalized or not represented in its evolutionarily developed linguistic systemicity. The latter process under the guise "language game," language as a tool, is what Wittgenstein captures in his second treatise on language as developed in the Philosophical Investigations. That is, the classes and categories identified and created by the dominant social class language game of a material resource framework constitute reified classes, categories, and forms of life, "language games," whose meanings and praxes as defined by the dominant social class language game are either accepted or deferred by those classified in them.

So, in Mocombe's theory of phenomenological structuralism, Wittgenstein's two theories of language and meaning must be read as one philosophy as opposed to two, one supported by analytical philosophy and the other by postmodernism/post-structuralism. We have a plethora of language games (classes, forms of life, and categories) in the world, which structures our language, because of the ability to defer meaning in ego-centered communicative discourse and the developmental stage of the human mind and body vis-à-vis the actual structure of reality. The language of science, like its predecessor religion, attempts to capture the logical-empirical structure of (quantum and physical) reality, and how we ought to live within it, amidst the utterances and practical consciousnesses of the masses given their abilities to defer meaning in ego-centered communicative discourse and the classes, categories, and forms of life they are classed in/with by the dominant social class language game.

Hence in the end, consciousness (praxis) and subject constitution is a product of conflict, or lack thereof, and an individual's (mental/cognitive) stance, i.e., analytics, vis-à-vis three structures of signification and the ability to defer meaning in ego-centered communicative discourse stemming from the social class language game (i.e., language, symbols, ideology, ideological apparatuses, and communicative discourse) of those who control the mode of production of a material resource framework. It is the ready-to-hand drives of the body and brain, ready-to-hand and present-at-hand manifestation of past/present/future recycled/ entangled/superimposed residual consciousnesses/subatomic particles, the present-at-hand phenomenological meditation and deferment of meaning that occurs in embodied consciousness via language, ideology, and communicative discourse as reflected in diverse individual practices, within the ready-to-hand, unready-tohand, and present-at-hand differentiating logic or class divisions of the social relations of production, which produces the variability of actions and practices in cultures, social structures, or social systems. All four types of actions, the (chemical, biological, and physiological) drives/impulses of the body and residual past/present/future consciousnesses of subatomic particles, structural reproduction/ differentiation, and actions resulting from the deferment of meaning in ego-centered communicative discourse, are always present and manifested in a social structure (which is the reified ideology via ideological apparatuses, their social class language game, of those who control a material resource framework) to some degree contingent upon the will and desires of the economic social class that controls the material resource framework through the actions of their bodies (practical consciousness), language, symbols, ideology, ideological apparatuses, and social relations of production. They choose, amidst the evolutionary class division of the social relations of production, "the structure of the conjuncture," (Marshall Sahlins's term) what other meaning constitutions and practices are allowed to manifest themselves without the Beings of that practice facing alienation, marginalization, domination, or death.

The individual being is initially constituted as superimposed, entangled, recycled, and embodied subatomic particles of multiple worlds of the multiverse, which have their own predetermined form of understanding and cognition, phenomenal properties, based on previous or simultaneous/entangled/superimposed experiences as aggregated matter (this is akin to what the Greek philosopher Plato refers to when he posits knowledge as recollection of the Soul). Again, the individual's actions are not necessarily determined by the embodiment and interconnecting drives of these recycled/ entangled/superimposed subatomic particles. It is conflict and an individual's stance, ready-to-hand, unready-to-hand, and presentat-hand, when the subatomic particles become aggregated matter or embodied, which determines whether are not they become aware, present-at-hand, of the subatomic particle drives and choose to recursively reorganize and reproduce the content of the drives as their practical consciousness.

This desire to reproduce the cognition and understanding of the (chemical, biological, and physiological) drives (frequency) of the recycled/entangled/superimposed subatomic particles, however, may be limited by the structuring structure of the aggregated body and brain of the individual subject. That is to say, the second origins and basis of an individual's actions are the structuring drives and desires, for food, clothing, shelter, social interaction, and sex, of the aggregated body and brain, which the subatomic particles constitute and embody. In other words, the aggregated body and brain is preprogrammed with its own (biological) forms of sensibility, understanding, and cognition, structuring structure, by which it experiences being-in-the-world as aggregated embodied subatomic particles. These bodily forms of sensibility, understanding, and cognition, such as the drive and desire for food, clothing, shelter, social interaction, linguistic communication, and sex, are tied to the material embodiment and survival of the embodied individual actor, and may or may not supersede or conflict with the desire and drive of an individual to recursively (re) organize and reproduce the structuring structure of the superimposed, entangled, and recycled (phenomenal properties of) subatomic particles. If these two initial structuring structures are in conflict, the individual moves from the ready-to-hand to the unready-to-hand stance or analytics where they may begin to reflect upon and question their being-in-theworld prior to acting. Hence just as in the case of the structuring structure of the subatomic particles it is an individual being's analytics vis-à-vis the drives of its body and brain in relation to the 
impulses of the subatomic particles, which determines whether or not they become driven by the desire (actions/praxis) to solely fulfill the material needs of their body and brain at the expense of the drives/desires of the subatomic particles or the social class language game of the material resource framework they find their existence unfolding in.

The social class language game, and its differentiating effects, an individual find their existence unfolding in is the third structuring structure, which attempts to determine the actions of individual beings as they experience being-in-the-world as embodied subatomic particles. The aggregated individual finds themselves objectified and unfolding within a material resource framework controlled by the actions of other bodies, which presuppose their existence, via the evolutionary actions of their bodies (practical consciousness), language, communicative discourse, ideology, and ideological apparatuses stemming from how they satisfy the desires of their bodies and subatomic particle drives (means and mode of production). What is aggregated as a social class language game by those in power positions via and within its mode of production, language, ideology, ideological apparatuses, and communicative discourse attempts to interpellate and subjectify other beings to its interpretive frame of satisfying their bodily needs, fulfilling the impulses of their subatomic particles, and organizing a material resource framework at the expense of all others, and becomes a third form of structuring individual action based on the mode of production and how it differentiates individual actors.

That is to say, an individual's interpellation, subjectification, and differentiation within the social class language game that presupposes their being-in-a-world attempts to determine their actions or practical consciousness via the reified language, ideology, etc., of the social class language game, the meaning of which can be deferred via the communicative discourse of the individual actors. Hence, the deferment of meaning in ego-centered communicative discourse of the language and ideology of a social class language game is the final means of determining an individual's action or practical consciousness outside of, and in relation to, its stance, i.e., analytics, vis-à-vis the drives of subatomic particles, drives and desires of the body and brain, and structural reproduction and differentiation.

Whereas the practical consciousness of the transcendental ego stemming from the impulses of embodied subatomic particles are indeterminant as with its neuronal processes involved with the constitution of meaning in ego-centered communicative discourse (Albeit physicists are in the process of exploring the nature, origins, and final states of subatomic particles, and neuroscientists are attempting to understand the role of neuronal activitiesin developing the transcendental ego and whether or not it continues to exist after death). The form of the understandings and sensibilities of the body and brain are determinant as with structural reproduction and differentiation of the mode of production and physiological mapping of the brain and body, and therefore can be mapped out by neuroscientists, biologists, and sociologists to determine the nature, origins, and directions of societal constitution and an individual actor's practical consciousness unfolding.

The interaction of all four elements or processes in relation to the stance of the transcendental ego of the individual actor is the basis for human action, praxis/practical consciousness in a world. However, in the end, consequently, the majority of practical consciousness will be a product of an individual actor's embodiment and the structural reproduction and differentiation of a social class language game given 1) the determinant nature of embodiment, form of understanding and sensibility of the body and brain amidst, paradoxically, the indeterminacy of impulses of embodied subatomic particles and the neuronal processes involved in ego-centered communicative discourse; and 2) the consolidation of power of those who control the material resource framework wherein a society, the social class language game, is ensconced and the threat that power (consolidated and constituted via the actions of bodies, mode of production, language, ideology, ideological apparatuses, and communicative discourse) poses to the ontological security of an aggregated individual actor who chooses (or not) either ready-to-hand or present-at-hand to recursively reorganize and reproduce the ideals of the society as their practical consciousness. It should be mentioned that in response to this latter process, those in power positions who internalize the ideals of the social structure and recursively (re) organize and reproduce them as their practical consciousness are in the unready-to-hand stance when they encounter alternative forms of being-in-theworld within their social class language game. They dialectically attempt to reconcile the practical consciousness of their social class language game with the reified practical consciousness of those who have deferred their meanings for alternative forms of being-inthe-world within their social class language. They can either accept, marginalize, or seek to eradicate the deferred or decentered subject or their practices [39-41].

Future research must continue to find evidence for the superverse, multiverse, and the subatomic particle, psychion, and its field, which is consciousness.

\section{Acknowledgement}

None.

\section{Conflicts of Interest}

No conflicts of interest.

\section{References}

1. Sklair, Leslie (1995) Sociology of the Global System. Westview Press, Baltimore, Maryland, USA.

2. Hameroff, Stuart, Roger Penrose (2014) Consciousness in the Universe: A Review of the 'Orch OR' theory. Physics of Life Reviews 11: 39-78.

3. Mocombe, Paul C (2016) The Vodou Ethic and the Spirit of Communism: The Practical Consciousness of the African People of Haiti. University Press of America, Maryland, USA.

4. Frank, Adam (2017) Minding Matter. Aeon.

5. Mocombe, Paul C (2019) The Theory of Phenomenological Structuralism. Newcastle upon Tyne, Cambridge Scholars Publishing, UK. 
6. Frankish Keith (2016) Why Panpsychism Fails to Solve the mystery of Consciousness. Aeon.

7. Althusser, Louis (2001) Lenin and Philosophy and Other Essays. Monthly Review Press, New York, USA.

8. Althusser, Louis, Étienne Balibar (1970) Reading Capital (Ben Brewster, Trans). NLB, London.

9. Balibar, Etienne, Immanuel Wallerstein (1991) Race, Nation, Class: Ambiguous Identities. Verso, London.

10. Buck-Morss, Susan (2009) Hegel, Haiti, and Universal History. University of Pittsburgh Press, Pittsburgh, Pennsylvania, USA.

11. Cohen J, (2002) Protestantism and Capitalism: The Mechanisms of Influence. Aldine de Gruyter, New York, USA.

12. Crothers, Charles (2003) Technical Advances in General Sociological Theory: The Potential Contribution of Post-Structurationist Sociology. Perspectives 26: 3-6.

13. Dahrendorf, Ralf (1959) Class and Class Conflict in Industrial Society. Stanford, Stanford University Press, California, USA.

14. Douglas M (1986) How Institutions Think. Syracuse University Press, New York, USA.

15. Du Bois, Laurent (2004) Avengers of the New World. Harvard University Press, Massachusetts, USA

16. Fraser Nancy (1997) Justice Interruptus: Critical Reflections on the "Postsocialist" Condition. Routledge, New York \& London.

17. Holloway, Joseph E (1990a) Africanisms in American Culture. Indiana University Press, Bloomington and Indianapolis.

18. Holloway, Joseph E (1990b) The Origins of African American Culture. In Joseph Holloway (Eds.), Africanisms in American Culture (19-33). Indiana University Press, Bloomington and Indianapolis.

19. Horkheimer Max, Theodor W, Adorno (2000) Dialectic of Enlightenment (John Cumming, Trans). Continuum, New York, USA.

20. Hudson, Kenneth, Andrea Coukos (2005) The Dark Side of the Protestant Ethic: A Comparative Analysis of Welfare Reform. Sociological Theory 23(1): 1-24.

21. James CLR (1986) The Black Jacobins: Toussaint L Ouverture and the San Domingo Revolution. Vintage.

22. Karenga, Maulana (1993) Introduction to Black Studies. The University of Sankore Press, California, USA

23. Kellner Douglas (2002) Theorizing Globalization. Sociological Theory 20: 285-305.

24. Kurtz, Lester R (2007) Gods in the Global Village: The World's Religions in Sociological Perspective. Sage Publications, California, USA.
25. Lukács, Georg (1971) History and Class Consciousness: Studies in Marxist Dialectics (Rodney Livingstone, Trans). Cambridge, The MIT Press, Massachusetts, USA.

26. Lukács, Georg (2000) A Defence of History and Class Consciousness: Tailism and the Dialectic (Esther Leslie, Trans). London and New York, Verso.

27. Marcuse, Herbert (1964) One-Dimensional Man. Beacon Press, Boston, USA.

28. Marcuse, Herbert (1974) Eros and Civilization: A Philosophical Inquiry into Freud. Beacon Press, Boston, USA.

29. Marx, Karl, Friedrich Engels (1964) The Communist Manifesto. London, Penguin Books, England.

30. Marx, Karl (1992 [1867]) Capital: A Critique of Political Economy (Volume 1, Samuel Moore and Edward Aveling, Trans). International Publishers, New York, USA.

31. Marx, Karl (1998 [1845]) The German Ideology. Prometheus Books, New York, USA.

32. Mc Michael, Philip (2008) Development and Social Change: A Global Perspective. Sage Publications, Los Angeles California, USA

33. Mocombe, Paul C (2009) The Soul-less Souls of Black Folk: A Sociological Reconsideration of Black Consciousness as Du Boisian Double Consciousness. University Press of America, Maryland, USA.

34. Ortner, Sherry (1984) Theory in Anthropology Since the Sixties, Comparative Studies in Society and History 26:126-66.

35. Patterson, Orlando (1982) Slavery and Social Death: A Comparative Study. Harvard University Press, Cambridge, Massachusetts.

36. Price, Huw and Ken Wharton (2016) Taming the Quantum Spooks. Aeon.

37. Ramsey, Kate (2011) The Spirits and the Law: Vodou and Power in Haiti. University of Chicago Press, Chicago, Illinois.

38. Rubin, Vera (1960) Caribbean Studies: A Symposium. University of Washington Press, Seattle, Washington.

39. Smith MG (1960) The African Heritage in the Caribbean. In Vera Rubin (Ed.), Caribbean Studies: University of Washington Press Symposium, Seattle, Washington, pp. 34-46.

40. Wallerstein, Immanuel (1982). The Rise and Future Demise of the World Capitalist System: Concepts for Comparative Analysis. In Hamza Alavi, Teodor Shanin (eds) Introduction to the Sociology of Developing Societies. Monthly Review Press, New York, USA, pp. 29-53

41. Weber, Max (1958 [1904-1905]). The Protestant Ethic and the Spirit of Capitalism (Talcott Parsons, Trans.). Charles Scribner's Sons, New York, USA. 